SCIENTIFIC REPORT

\title{
Efficacy of core vitrectomy preceding triple corneal procedure
}

\author{
K Konomi, J Shimazaki, S Shimmura, N Akabane, E Goto, K Tsubota
}

Br J Ophthalmol 2004;88:1023-1025. doi: 10.1136/bjo.2003.033902

\begin{abstract}
Aims: To evaluate the effectiveness of core vitrectomy preceding triple corneal procedure (penetrating keratoplasty, extracapsular cataract extraction, and intraocular lens (IOL) implantation).

Methods: Thirty one consecutive eyes of 31 patients with indication for triple corneal procedure were randomly assigned to either triple procedure with core vitrectomy (vitrectomy group) or without vitrectomy (control group). The success rate of $\mathrm{IOL}$ implantation, $\mathrm{IOL}$ positioning, intraoperative and postoperative complications, endothelial cell loss, and best corrected visual acuity (BCVA) were compared. Follow up period was six months. Factors that may contribute to vitreous pressure elevation were also investigated in each case.

Results: There was no statistically significant difference in each clinical parameter examined except a tendency of facilitating IOL implantation $(p=0.11)$. There were two cases of vitreous loss in the control group. Retinal detachment was not seen in any of the cases. The body mass index and age were related to higher vitreous pressure $(p<0.05)$.

Conclusion: Core vitrectomy preceding triple corneal procedure is not necessary for all cases.
\end{abstract}

$\mathrm{T}$ riple corneal procedure (penetrating keratoplasty, extracapsular cataract extraction (ECCE), and intraocular lens implantation (IOL)) has become the standard treatment for patients with corneal opacity and cataract. ${ }^{1-5}$ As vitreous pressure is one of the most important factors to consider in order to accomplish this procedure safely, several methods have been attempted to reduce preoperative pressure. ${ }^{6}$ Standard prophylaxis such as ocular compression and administration of osmotic agents is easily performed, ${ }^{89}$ but sometimes ineffective in reducing vitreous pressure sufficiently. Core vitrectomy preceding triple corneal procedure is sometimes performed to reduce vitreous volume and to prevent the vitreous pressure from increasing. ${ }^{10}{ }^{11}$ However, there have been no prospective studies that have evaluated patients with and without core vitrectomy preceding triple corneal procedure. In the present study, we examine the efficacy and safety of core vitrectomy compared with standard treatments.

\section{MATERIALS AND METHODS}

The study was conducted in a prospective, randomised fashion where patients were randomly assigned based on a surgical chart number. Patients with odd numbers were assigned to triple procedure with core vitrectomy, and those with even numbers to triple procedure without core vitrectomy.

Patients requiring penetrating keratoplasty and cataract surgery were enrolled between March 2001 and October 2002 in the Department of Ophthalmology, Tokyo Dental College. All patients received information about the purpose of the study as well as advantages and disadvantages of core vitrectomy. Informed consent was obtained from all patients who agreed to participate in the study. As a result, 32 eyes of 32 patients were enrolled and randomly assigned to either triple procedure with core vitrectomy $(n=15)$ or without core vitrectomy $(n=17)$ according to the study design described above. Surgery was performed by three surgeons (KT, JS, and SS).

One eye in the vitrectomy group was excluded from this study because of retrobulbar haemorrhage. The vitrectomy group consisted of three males (three eyes) and 11 females (11 eyes) with a mean (standard deviation) age of 66.6 (SD 8.9) years (range 49-78 years). The control group consisted of four males (four eyes) and 13 females ( 13 eyes) with a mean age of 73.2 (SD 7.5) years (range 61-83 years). Statistical difference was seen in the average age between two groups $(p=0.034)$. The original disease in each group is shown in table 1 .

\section{Surgical methods}

Ocular compression was performed preoperatively with a pneumatic pressure device set at $40 \mathrm{~mm} \mathrm{Hg}$ for 15 minutes. Acetazolamide $(250 \mathrm{mg}$ ) was administered one hour before surgery, but intravenous osmotic agents were not administered. All patients were operated under retrobulbar anaesthesia with 2\% lidocaine (Xylocaine, Fujisawa Pharmaceutical Co, Osaka, Japan).

In the core vitrectomy group, a single sclerotomy was made $3.5 \mathrm{~mm}$ posterior to the corneal limbus in the superotemporal quadrant. A vitreous cutter was inserted $10-12 \mathrm{~mm}$ into the centre of the vitreous cavity and vitreous was excised and approximately $0.3 \mathrm{ml}$ was aspirated. After digitally confirming the reduction of ocular pressure, the sclerotomy was closed with interrupted 8-0 vicryl sutures avoiding vitreous herniation.

Triple corneal procedure was then performed in a standardised fashion. A scleral ring was fixed to the globe with 6-0 silk sutures. Anterior Chamber was filled with Healon (sodium hyaluronate, Pharmacia \& Upjohn Co, Kalamazoo, MI, USA) and then the recipient cornea was excised using the $7.5 \mathrm{~mm}$ diameter Hessbarg-Barron trephine (Katena Products Inc, Denville, NJ, USA). After excision of the cornea, continuous curvilinear capsulorhexis was performed with the $4.5 \mathrm{~mm}$ diameter motor trephine (MicroKeratoron, Geuder AG, Heidelberg, Germany) or capsular forceps and ECCE was performed. Simco Cortex Extractor (Katena) was used to aspirate residual cortex with the aspiration-irrigation soft contact lens which stabilised the anterior chamber ${ }^{12}$ during cortex aspiration. An $8.0 \mathrm{~mm}$ or

Abbreviations: $B C V A$, best corrected visual acuity; $B M I$, body mass index; ECCE, extracapsular cataract extraction; ICCE, intracapsular cataract extraction; IOL, intraocular lens. 


\begin{tabular}{|c|c|c|c|}
\hline & $\begin{array}{l}\text { Vitrectomy } \\
\text { group }\end{array}$ & $\begin{array}{l}\text { Control } \\
\text { group }\end{array}$ & p Value \\
\hline Number of subjects & 14 & 17 & \\
\hline Mean (SD) age (years) & $66.6(8.9)$ & $73.2(7.5)$ & $0.034^{*}$ \\
\hline Sex/male & & & $1.0+$ \\
\hline $\begin{array}{l}\text { Mean (SD) axial length } \\
(\mathrm{mm})\end{array}$ & $23.9(2.7)$ & $22.6(1.6)$ & $0.10^{*}$ \\
\hline Mean (SD) BMI & $24.0(4.5)$ & $22.7(3.6)$ & $0.37^{*}$ \\
\hline History of glaucoma & 1 & 1 & $1.0 \dagger$ \\
\hline \multicolumn{4}{|l|}{ Diagnosis } \\
\hline Bullous keratopathy & 6 & 9 & $0.72 \dagger$ \\
\hline Herpetic keratitis & 2 & 2 & $1.0+$ \\
\hline Leukoma & 5 & 6 & $1.0 \dagger$ \\
\hline Chemical burn & 1 & 0 & $0.45 \dagger$ \\
\hline \multicolumn{4}{|c|}{$\begin{array}{l}\text { SD, standard deviation; BMI, body mass index. } \\
{ }^{*} \text { Two tailed } t \text { test. } \\
\text { tFisher's exact test. }\end{array}$} \\
\hline
\end{tabular}

$7.75 \mathrm{~mm}$ donor button was punched out using the Barron donor punch (Katena). Healon (Pharmacia \& Upjohn) was injected to dilate the capsular bag and IOL was implanted in the bag in the open sky condition. If the posterior capsule was elevated above the iris because of vitreous pressure, IOL implantation was performed after temporarily suturing the donor cornea with 10-0 nylon sutures. The donor cornea was secured to the recipient's cornea with 10-0 nylon single continuous running suture.

After surgery, intraoperative suture adjustment was performed in both groups. ${ }^{13}$ Extended wear soft contact lenses were placed, and subconjunctival corticosteroids and antibiotics were given.

Eyes in both groups received topical $0.5 \%$ levofloxacin (Cravit, Santen Pharmaceutical Co, Osaka, Japan) and 0.1\% betamethasone (Sanbetason, Santen) five times a day.

The efficacy of core vitrectomy was determined by comparing the success rate of IOL implantation, IOL positioning, the timing of IOL implantation, and intraoperative complications. Postoperative complications, endothelial cell loss, and best corrected visual acuity (BCVA) were also compared in the two groups. Body mass index (BMI) was measured in every case. Fisher's exact test was used for statistical analysis. Differences in corneal endothelial density loss, age, BMI, and axial length were analysed using the unpaired $t$ test. The average BCVA of both groups was compared using Mann-Whitney's U test. A p value of less than 0.05 was considered significant. The postoperative follow up period was 6 months.

\section{RESULTS}

The surgical results and postoperative complications are shown in table 2 .

Statistical differences between the two groups were not seen in all parameters. However, the success rate of implanting an IOL in the capsular bag was slightly higher in the vitrectomy group compared with control $(p=0.11)$.

In the vitrectomy group, the success rate of IOL implantation was 13 of 14 eyes $(92.8 \%)$. The IOL was implanted in the bag in 11 of 13 eyes (84.6\%). IOL implantation was not performed in one eye because of an unplanned intracapsular cataract extraction (ICCE), and two eyes had the IOL out of the bag (into the ciliary sulcus or the sulcus and the bag). The IOL was implanted under the open-sky condition in 11 of 13 eyes $(84.6 \%)$ of the patients.

Endothelial cell loss was $18.9 \%$ at the 6 month postoperative follow up examination with an average BCVA of 0.24 . No vitreous herniation or loss occurred; however there was one eye with an unplanned ICCE. No other intraoperative complications were seen in this group. Postoperatively,
Table 2 Clinical results

\begin{tabular}{|c|c|c|c|}
\hline & $\begin{array}{l}\text { Vitrectomy } \\
\text { group }(n=14)\end{array}$ & $\begin{array}{l}\text { Control group } \\
(n=17)\end{array}$ & p Value \\
\hline $\begin{array}{l}\text { Success in } \mathrm{IOL} \\
\text { implantation }\end{array}$ & $13(92.8 \%)$ & $16(94.1 \%)$ & $0.71^{*}$ \\
\hline $\mathrm{IOL}$ in the bag & $\begin{array}{l}11(84.6 \%) \\
(n=13)\end{array}$ & $\begin{array}{l}9(56.3 \%) \\
(n=16)\end{array}$ & $0.11^{*}$ \\
\hline $\begin{array}{l}\text { Intraoperative } \\
\text { complications }\end{array}$ & 1 & 4 & $0.23^{*}$ \\
\hline $\begin{array}{l}\text { Capsular rupture or } \\
\text { vitreous loss }\end{array}$ & 1 & 2 & $0.29^{*}$ \\
\hline Unplanned ICCE & 1 & 1 & $0.71 *$ \\
\hline Iris damage & 0 & 2 & $0.29^{*}$ \\
\hline $\begin{array}{l}\text { Postoperative } \\
\text { complications }\end{array}$ & 4 & 5 & $0.59^{*}$ \\
\hline Ocular hypertension & 3 & 3 & $0.57^{*}$ \\
\hline $\begin{array}{l}\text { IOL capture or } \\
\text { posterior synechia }\end{array}$ & 2 & 3 & $0.60^{*}$ \\
\hline $\begin{array}{l}\text { Persistent epithelial } \\
\text { defect }\end{array}$ & 1 & 0 & $0.45^{*}$ \\
\hline Graft rejection & 0 & 0 & \\
\hline $\begin{array}{l}\text { Retinal detachment } \\
\text { or oedema }\end{array}$ & 0 & 0 & \\
\hline $\begin{array}{l}\text { Corneal endothelial } \\
\text { cell loss }\end{array}$ & $18.9 \%$ & $22.1 \%$ & $0.84 \dagger$ \\
\hline BCVA & 0.24 & 0.25 & $0.80 \ddagger$ \\
\hline \multicolumn{4}{|c|}{$\begin{array}{l}\text { IOL, intraocular lens; ICCE, intracapsular cataract extraction; BCVA, best } \\
\text { corrected visual acuity. } \\
\text { *Fisher's exact test. } \\
\text { †two tailed } t \text { test. } \\
\text { †Mann-Whitney U test. }\end{array}$} \\
\hline
\end{tabular}

there were two cases of IOL capture or posterior synechia, three cases of ocular hypertension, and one case of persistent epithelial defect.

In the control group, the success rate of IOL implantation was 16 of 17 eyes $(94.1 \%)$. The IOL was implanted in the bag in nine of 16 eyes $(56.3 \%)$ of the patients. IOL implantation was not performed in one eye because of an unplanned ICCE, and seven eyes with the IOL out of the bag. The IOL was implanted under the open sky condition in nine of 16 eyes $(56.3 \%)$ of the patients. Endothelial cell loss was $22.1 \%$ at the 6 month postoperative follow up examination with an average BCVA of 0.25 .

There were two cases of vitreous loss because of interoperative complications. Unplanned ICCE was performed in one of these cases. Iris damage was observed in two eyes. Postoperatively, there were three cases of IOL capture or posterior synechia and three cases of ocular hypertension. Retinal detachment and cystoid macular oedema were not seen in either group.

On the other hand, the comparison of preoperative characteristics between vitreous loss or unplanned ICCE cases and other cases is shown in table 3. Of three cases with vitreous loss or unplanned lens extraction, the average BMI $(\mathrm{BMI}=28.1) \quad$ was higher than that of the others $(B M I=22.5)(p=0.03)$. The mean age (63 (SD 3.5) years, range 61-67 years) of these three cases was lower than that (71 (SD 8.8) years range 49-83 years) of the others $(p=0.027)$. There was no relation between the axial length and vitreous loss $(\mathrm{p}=0.34)$.

\section{DISCUSSION}

To perform the triple procedure safely, some preventative measures have been attempted to reduce vitreous pressure and there have been some studies that supported the efficacy of vitrectomy or vitreous aspiration. ${ }^{7}{ }^{10}{ }^{11}$ In this study, we designed a prospective randomised clinical trial to evaluate the efficacy of core vitrectomy.

In the vitrectomy group, there was no vitreous loss or herniation, whereas there were two cases of vitreous loss in 
Table 3 Comparison of preoperative characteristics between vitreous loss or unplanned ICCE cases and the other cases

\begin{tabular}{llll}
\hline & $\begin{array}{l}\text { Vitreous loss (+) or } \\
\text { unplanned ICCE }\end{array}$ & $\begin{array}{l}\text { Other } \\
\text { cases }\end{array}$ & p Value \\
\hline $\begin{array}{l}\text { Number of } \\
\text { subjects }\end{array}$ & 3 & 28 & \\
$\begin{array}{l}\text { Mean (SD) } \\
\text { age (years) }\end{array}$ & $63(3.5)$ & $71(8.8)$ & $0.027^{*}$ \\
$\begin{array}{l}\text { Mean (SD) axial } \\
\text { length (mm) }\end{array}$ & $22.3(1.1)$ & $23.3(2.3)$ & $0.27^{*}$ \\
$\begin{array}{l}\text { Mean (SD) BMl } \\
\text { History of } \\
\text { glaucoma }\end{array}$ & $28.1(3.1)$ & $22.8(3.8)$ & $0.03^{*}$ \\
\hline
\end{tabular}

$\mathrm{SD}$, standard deviation.

*Two tailed $t$ test.

†Fisher's exact test.

the control group. Posterior capsular rupture usually occurred during aspiration of residual cortex because of increased vitreous pressure pushing the capsule forward. In this study, the same condition was seen in only one eye in the control group. In the other two cases, the crystalline lenses came out spontaneously after corneal excision in the open sky condition and an unplanned ICCE was performed in each case. The unplanned ICCE case in the vitrectomy group did not require additional anterior vitrectomy as there was no vitreous loss. This indicates that the anterior vitreous face was intact, and that core vitrectomy was effective in reducing the vitreous volume.

The rate of posterior capsular rupture during the triple corneal procedure varies according to studies (4.0-40\%). ${ }^{71}$ In our institute, the rate was $0 \%$ in the core vitrectomy group and $5.9 \%$ in the control group. Core vitrectomy reduced vitreous pressure, and may ameliorate the feasibility of the IOL implantation $(p=0.11)$ in the bag, though there was no significant difference in the two groups. The precise reason is unknown but it may be related not only to the volume of residual vitreous but also the zin zonule and other factors.

Postoperatively, there were no significant differences between the two groups in visual acuity or endothelial cell loss.

The disadvantages of core vitrectomy preceding triple corneal procedure include additional time required to perform surgery, and difficulty in suturing the cornea under hypotony. There was no severe retinal complication such as retinal detachment in the vitrectomy group, but there are some risks compared with the control group. Some studies have shown increased incidence of retinal detachment and retinal oedema. ${ }^{14} 15$ If the hyaloid face is disrupted, the incidence of cystoid macular oedema is significantly higher ${ }^{16}$ so pars plana vitrectomy or vitreous aspiration is preferred rather than through the pupil if the vitreous face is intact.

There are some predisposing factors for increased vitreous pressure. Age, obesity (high BMI), anaesthesia, eyelid pressure, blood pressure, and a history of glaucoma are thought to be factors. Controlling these factors is also important to prevent complications. In the present study, we also evaluated the relation between vitreous loss or unplanned ICCE and age, axial length, BMI, and history of glaucoma. We found that axial length and history of glaucoma were not related, but age and BMI were related to these complications. The mean age of the vitrectomy group was also statistically younger than that of the control group $(p=0.034)$. This might have had some influence of increasing the risk of these complications of the vitrectomy group; however, there was no case of vitreous loss in this group. This result may support the effectiveness of core vitrectomy. Consequently, some preventative procedures must be taken to avoid complications if the patient has a high BMI, or is of a younger age.

Effective orbital and lid anaesthesia and the positioning of the lid speculum are important to minimise the external pressure on the globe. Lateral canthotomy is also useful if the palpebral fissure is narrow.

Core vitrectomy preceding triple corneal procedure is not necessary for all cases, but in some cases, core vitrectomy may be considered to facilitate IOL implantation.

\section{Authors' affiliations}

K Konomi, J Shimazaki, S Shimmura, N Akabane, E Goto, K Tsubota, Department of Ophthalmology, Tokyo Dental College, Ichikawa, Japan

Correspondence to: Dr K Konomi, Department of Ophthalmology, Tokyo Dental College, Ichikawa General Hospital, Sugano 5-11-13, Ichikawa City, Chiba 272-8513, Japan; jzt02060@nifty.ne.jp

Accepted 17 January 2004

\section{REFERENCES}

1 Taylor DM. Keratoplasty and intraocular lenses. Ophthalmic Surg 1976;7:31-42.

2 Taylor DM, Khalig A. Keratoplasty and intraocular lenses: follow-up study. Ophthalmic Surg 1977;8:49-57.

3 Taylor DM, Khaliq A, Maxwell R. Keratoplasty and intraocular lenses: current status. Ophthalmology 1979;86:242-55.

4 Lindstrom RL, Harris WS, Doughman DJ. Combined penetrating keratoplasty, extracapsular cataract extraction, and posterior chamber lens implantation. J Am Intraocul Implant Soc 1981;7:130-2.

5 Hunkeler JD, Hyde LL. The triple procedure: combined penetrating keratoplasty, extracapsular cataract extraction and lens implantation. An expanded experience. J Am Intraocul Implant Soc 1983;9:20-4.

6 McCartney DL, Gottsch JD, Stark WJ. Managing posterior pressure during pseudophakic keratoplasty. Arch Ophthalmol 1989;107:1384-6.

7 Meyer RF, Musch DC. Assessment of success and complications of triple procedure surgery. Am J Ophthalmol 1987; 104:233-40.

8 Sud RN, Loomba R. Achievement of surgically soft and safe eyes-a comparative study. Indian J Ophthalmol 1991;39:12-4.

9 Guindon B, Harvey J, Peacocke A, et al. Factors modifying vitreous pressure in cataract surgery. Can J Ophthalmol 1981;16:73-5.

10 Shimomura $Y$, Hosotani $\mathrm{H}$, Kiritoshi A, et al. Core vitrectomy preceding triple corneal procedure in patients at high risk for increased posterior chamber pressure. Jpn J of Ophthalmol 1997;41:251-4.

11 Schanzlin DJ, Smith RE. Management of an intact vitreous face in penetrating keratoplasty. Ophthalmic Surg 1983;14:427-8.

12 Tsubota K. An aspiration-irrigation soft contact lens for maintenance of the anterior chamber. Am J Ophthalmol 1988;106:759-60.

13 Shimazaki J, Shimmura S, Tsubota K. Intraoperative versus postoperative suture adjustment after penetrating keratoplasty. Cornea 1998;17:590-4.

14 Musch DC, Meyer RF, Sugar A, et al. Retinal detachment following penetrating keratoplasty. Arch Ophthalmol 1986;104:1617-20.

15 Forstot SL, Binder PS, Fitzgerald C, et al. The incidence of retinal detachment after penetrating keratoplasty. Am J Ophthalmol 1975;80:102-5.

16 Kramer SG. Penetrating keratoplasty combined with extracapsular cataract extraction. Am J Ophthalmol 1985;100:129-33. 